1 Universidade Federal do Espírito Santo (Ufes), Programa de Pósgraduação em Saúde Coletiva - Vitória (ES) Brasil.

juliagarbois@hotmail.com

2 Universidade Federal do Espírito Santo (Ufes), Programa de Pósgraduação em Saúde Coletiva - Vitória (ES), Brasil.

francisodre@uol.com.br

3 Universidade Federal do Espírito Santo (Ufes), Programa de Pósgraduação em Saúde Coletiva - Vitória (ES), Brasil. Escola Superior de Ciências da Santa Casa de Misericórdia, Programa em Políticas Públicas - Vitória (ES), Brasil.

dalbello.araujo@gmail.com

\section{Da noção de determinação social à de determinantes sociais da saúde}

\author{
From the notion of social determination to one of social determinants \\ of health
}

Júlia Arêas Garbois', Francis Sodré2 ${ }^{2}$ Maristela Dalbello-Araujo ${ }^{\mathbf{3}}$

RESUMO O ensaio aborda criticamente a noção de determinantes sociais da saúde, veiculada oficialmente pela Organização Mundial da Saúde, a partir da discussão sobre sua perspectiva conceitual que difere bastante daquela cunhada por volta dos anos 1970, pela corrente médico-social latino-americana, de determinação social da saúde. A discussão desnuda os preceitos filosóficos que sustentam a noção de determinantes sociais da saúde, a partir dos argumentos fundados na sociologia positivista de Émile Durkheim. Conclui-se que essa noção identifica um 'social' fragmentado, trazendo consequências práticas e políticas e mostrando-se insuficiente para analisar as mudanças sociais da contemporaneidade.

PALAVRAS-CHAVE Ciências sociais. Medicina social. Saúde pública. Epistemologia. Processo saúde-doença.

ABSTRACT The article critically discusses the concept of social determinants of health, conveyed
officially by the World Health Organization, from the discussion of its conceptual perspective
that differs greatly from that coined around the 1970's by Latin American medical-social current,
of social determination of health. The discussion reveals the philosophical principles that
underpin the notion of social determinants of health from the arguments based by the positivist
sociology of Émile Durkheim. We conclude that such notion identifies a fragmented 'social', that
reflects practical and political consequences and it is insufficient to analyze the social changes of
contemporaneity. KEYWORDS Social sciences. Social medicine. Public health. Knowledge. Health-disease process. 


\section{Introdução}

Este ensaio objetiva discutir, do ponto de vista teórico-científico, a ideia de determinantes sociais da saúde, procurando demonstrar sua fragilidade e distanciamento em relação à noção de determinação social, oriunda da corrente de pensamento da medicina social latino-americana. Noção esta de grande importância para a demarcação do campo de conhecimento da saúde coletiva.

Para isso, entende-se ser pertinente revisitar a produção acadêmica latino-americana da década de 1970 sobre o conceito de saúde, marcada por intensas discussões conceituais que culminaram na perspectiva da determinação social do processo saúde-doença. Após, será feito um contraponto com as atuais propostas de abordagem desse processo, especialmente a partir da criação da Comissão dos Determinantes Sociais da Saúde, pela Organização Mundial da Saúde (OMS) com a proposta de trabalho erigida sobre uma noção bastante diferenciada daquela da década de 1970: a noção de determinantes sociais da saúde (TAMBELLINI; SCHÜTZ, 2009; NOGUEIRA, 2009).

Busca-se elucidar o arcabouço teórico subjacente à noção de determinantes sociais da saúde, a partir dos argumentos fundados na sociologia clássica, mais especificamente, na sociologia positivista de Émile Durkheim, no intuito de desvelar os preceitos filosóficos que lhe dão sustentação. Finaliza-se, estabelecendo considerações a respeito das implicações advindas da adoção da noção de determinantes sociais da saúde e de alguns dos desafios postos pela atualidade que envolve essa problemática, com contribuições de pensamentos de teóricos da sociologia como Latour (2012) e Santos (2008).

\section{Origens da noção de determinação social da saúde}

No final dos anos 1970, houve um profundo questionamento do paradigma biomédico da doença, que a conceituava como um fenômeno biológico individual. Esse movimento de crítica se situa em um contexto social marcado pela dificuldade da Medicina na produção de um novo conhecimento que fosse capaz de compreender e explicar a causalidade dos principais problemas de saúde que emergiam nos países industrializados, como as doenças cardiovasculares e os tumores malignos (LAURELL, 1983).

Nesse movimento questionador ao paradigma biomédico, a corrente da medicina social latino-americana trouxe importantes contribuições para a argumentação teórica sobre as condições de insuficiência das práticas médicas em oferecer soluções satisfatórias para a melhoria das condições de saúde da coletividade, demarcando a entrada de correntes do pensamento social na área da saúde, a partir da realização de uma nova leitura da saúde pública (FACCHINI, 1994; LAURELL, 1983; BRELLH, 1991; TAMBELLINI-AROUCA, 1984; AROUCA, 2003).

A argumentação partiu especialmente da crítica à abordagem positivista inscrita no modelo da história natural da doença, que interpretava o processo de adoecimento a partir de uma perspectiva 'naturalizada', centrada na causação linear e marcadamente biologicista. A abordagem sugerida pela corrente médico-social fundou-se, então, na recolocação da problemática da relação entre o processo social e o processo biológico, a partir da perspectiva da 'determinação’. Compreendeu a produção das doenças no plano da coletividade e construiu uma análise científica dos processos que operam como determinantes destas, por meio da ampliação da explicação do princípio da causalidade (LAURELL, 1983; BREILH, 1991).

Em 'Saúde e sociedade', Donnangelo (1979) compreendeu as complexas relações sociais existentes no processo de produção da saúde e da doença, por meio da análise dos vínculos que existem entre a extensão de cobertura dos cuidados médicos, os serviços de saúde e as necessidades do capitalismo no sentido de 
manter e reproduzir a força de trabalho, controlar as tensões e antagonismos sociais e realizar a acumulação de capital do setor industrial de equipamentos e de insumos médicos.

A ótica de análise passou a ser estabelecida pela abordagem da dimensão coletiva como produtora e reprodutora das formas, tanto de adoecimento, quanto de vitalidade. Ou seja, se a finalidade era compreender a saúde-doença como um fenômeno coletivo, o objeto de estudo não partia mais do indivíduo, mas sim do grupo. Dessa maneira, o objeto de estudo da corrente médico-social envolvido na produção de conhecimento passou a ser o processo saúde-doença coletivo:

Por processo saúde-doença da coletividade, entendemos o modo específico pelo qual ocorre no grupo o processo biológico de desgaste e reprodução, destacando como momentos particulares a presença de um funcionamento biológico diferente com consequência para o desenvolvimento regular das atividades cotidianas, isto é, o surgimento da doença. (LAURELL, 1983, P. 152).

A reformulação da natureza da doença, que passou a ser vista como um processo da coletividade - no qual o que interessa é o estudo do modo como o processo biológico acontece socialmente -, trouxe, como consequência, a mudança do léxico: 'de fator para processo'. Essa visão saúde-doença como resultante de um processo social traduziu-se na reinterpretação de suas causas: de entidades estáticas, passíveis de abstração formal, ao entendimento de seu caráter dinâmico, como parte integrante do "movimento global da vida social” (BREILH, 1991, P. 200).

O deslocamento de uma produção científica que migra de um 'fator social' para um 'processo social' cria o encadeamento de ideias que sugerem a formação de um novo campo. Um campo no qual o foco de análise recai sobre a necessidade de observação das leis históricas de produção e organização das sociedades na explicação das causas mais profundas das doenças, valorizando a essência dos fatos sociais, e não apenas as suas manifestações fenomênicas. Cria-se, a partir desse intenso debate teórico-conceitual, a noção de 'determinação social da saúde' como categoria analítica, com referencial teórico delimitado, para servir de base conceitual aos estudos desenhados com o propósito de ampliar a discussão sobre a produção coletiva da saúde.

Breilh (1991) propôs o arcabouço teórico-metodológico do materialismo histórico como uma possibilidade de integrar o ponto de vista popular e o rigor de um método de análise científica, uma ferramenta efetiva de transformação política. A partir dessa perspectiva, Tambellini-Arouca (1984) enfatiza as relações entre o trabalho e o processo saúde-doença. A partir de então, será essa a principal categoria retirada do pensamento marxista para auxiliar na leitura aos fenômenos considerados estritos à saúde, colocando no processo de trabalho a dimensão da determinação do processo de adoecimento, ao considerá-lo como o mediador das relações estabelecidas entre o homem e a natureza e entre os próprios homens.

\section{A noção de determinantes sociais da saúde}

Desde a virada do século, a temática da determinação social da saúde passou a ocupar uma posição central nos debates internacionais a respeito das relações entre a saúde e a sociedade. Entretanto, tal retomada entrou na agenda política mundial a partir de uma perspectiva teórico-metodológica bastante diferenciada daquela produzida pela corrente médico-social latino-americana, a epidemiologia social da década de 1970 (ALMEIDA-FILHO, 2010).

As discussões reaparecem sob a chancela de 'determinantes sociais da saúde' (DSS), no sentido de fomentar um intenso debate cujo foco principal de análise incide sobre o tema 'desigualdades', por meio da constatação de 
importantes disparidades nas condições de vida e de trabalho, no acesso diferenciado a serviços assistenciais, na distribuição desigual de recursos de saúde e nas suas repercussões sobre a morbidade e mortalidade entre os diferentes grupos sociais (ALMEIDA-FILHO, 2010).

Esse contexto de reaparecimento da temática foi, em grande parte, alavancado pela OMS quando, em 2005, criou uma comissão específica para discutir os determinantes sociais da saúde - Comissão para os Determinantes Sociais da Saúde (CDSS) - e convocou as autoridades dos países para a necessidade de chegar a uma decisão coletiva de combater as expressivas desigualdades em saúde.

A CDSS entende os determinantes sociais da saúde como as circunstâncias em que as populações crescem, vivem, trabalham e envelhecem, bem como os sistemas implementados para lidar com a doença,

circunstâncias tais que são moldadas, por outro lado, por "forças de ordem política, social e econômica" (COMISSÃO PARA OS DETERMINANTES SOCIAIS DA SAÚDE, 2010, P. 1). NesSe sentido, as condições de vida mostram-se determinadas pelo lugar que cada um ocupa na hierarquia social. Esse conceito, tal como elaborado pela comissão, foi inspirado no modelo de Dahlgren e Whitehead (COMISSÃo PARA OS DETERMINANTES SOCIAIS DA SAÚDE, 2010), e pode ser resumido conforme a figura 1 a seguir:

Figura 1. Modelo dos Determinantes Sociais da Saúde proposto por Dahlgren e Whitehead e adotado pela OMS

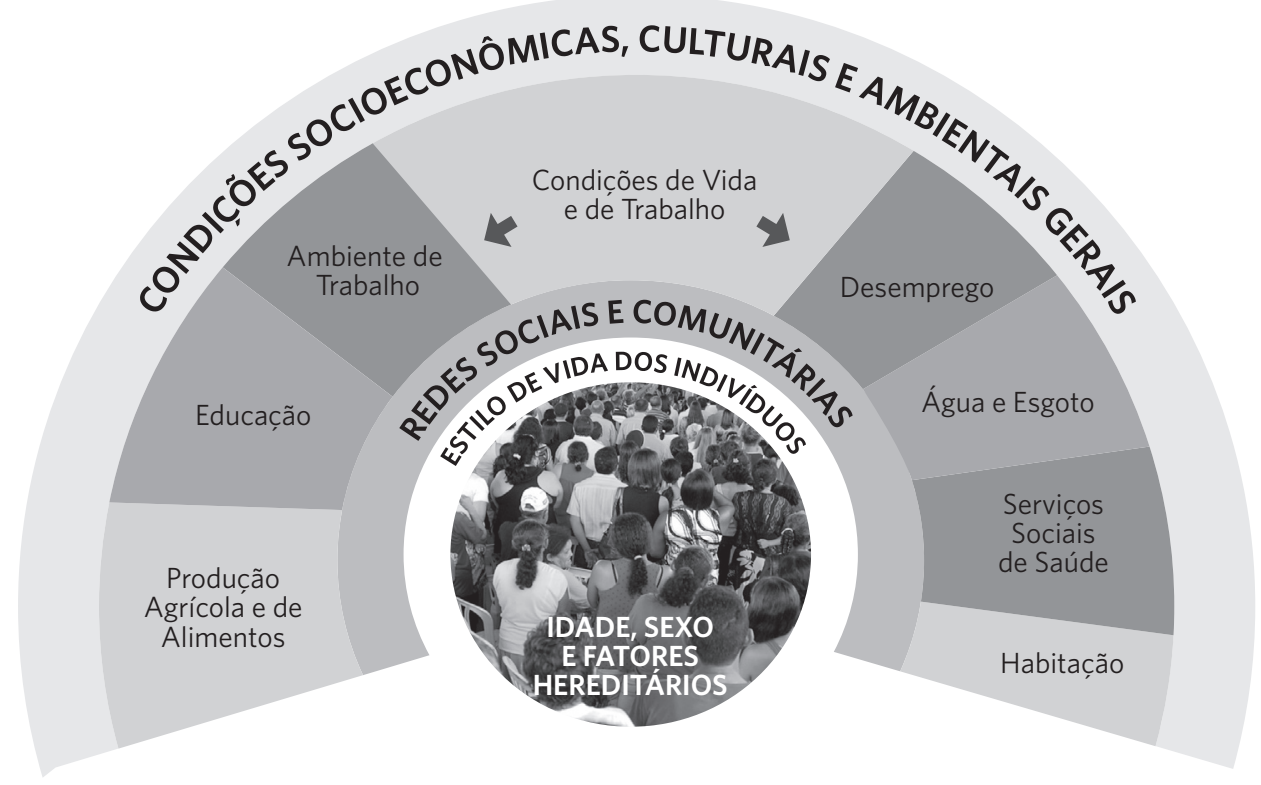

Fonte: Comissão Nacional sobre os Determinantes Sociais da Saúde (2008).

Nesse modelo, os determinantes sociais da saúde são abordados em camadas, desde aquelas que expressam as características individuais, até as que incluem os macrodeterminantes do processo saúde-doença.
Assim, conforme a figura, os indivíduos encontram-se na base desse modelo, com suas características individuais de idade, sexo e fatores genéticos. A camada seguinte, representada pelos comportamentos e 
estilos de vida individuais, encontra-se no limiar entre aqueles fatores individuais e os DSS, já que os comportamentos, além de serem dependentes de opções individuais, são também dependentes dos DSS, como o acesso a informações e alimentos saudáveis, lazer, entre outros. A camada seguinte é representada pelas redes comunitárias e de apoio, que conformam redes de solidariedade e expressam, em maior ou menor grau, de acordo com a sua organização, o nível de coesão social. Logo após, encontram-se os fatores relacionados com as condições de vida e de trabalho dos indivíduos, disponibilidade de alimentos, assim como o acesso a serviços essenciais, como saúde e educação, indicando os diferenciais de vulnerabilidade a que estão expostos os indivíduos que se encontram em condição de pobreza. Por fim, a última camada expressa os macrodeterminantes relacionados com as condições econômicas, sociais e ambientais em que vive a sociedade, assim como os determinantes supranacionais como o processo de globaliZação (COMISSÃO NACIONAL SOBRE OS DETERMINANTES SOCIAS DA SAÚDE, 2008).

Em 2010, a OMS estabelece um novo marco conceitual sobre os DSS, sintetizado a partir do modelo proposto por Solar e Irwin (2010), e que foi adotado no ano seguinte, na Conferência Mundial sobre os Determinantes Sociais da Saúde de 2011, sendo incluído no relatório 'Diminuindo diferenças: a prática das políticas sobre determinantes sociais da saúde' (ORGANIZAC̣̃̃o MUNDIAL DA SAÚDE, 2011). Nesse modelo (figura 2), os determinantes estruturais operam por meio de um conjunto de determinantes intermediários para moldar os efeitos na saúde. A 'estrutura' expressa como os mecanismos sociais, econômicos e políticos dão origem a um conjunto de posições socioeconômicas, em que as populações são estratificadas de acordo com a renda, a educação, a ocupação, o gênero, a raça/etnia e outros fatores. Essas posições socioeconômicas, por sua vez, determinam vulnerabilidades e exposições diferenciadas nas condições de saúde (determinantes intermediários) e refletem o lugar das pessoas dentro das hierarquias sociais. Entre os fatores contextuais relacionados com a produção e manutenção da hierarquia social, os autores destacam: 1) estruturas de governança formais e informais relacionadas com mecanismos de participação social da sociedade; 2) políticas macroeconômicas, incluindo políticas fiscais, monetárias, políticas de mercado e a estrutura do mercado laboral; 3) políticas sociais nas áreas de emprego, posse de terra e habitação; 4) políticas públicas em áreas como educação, saúde, água e saneamento, assim como a extensão e a natureza de políticas redistributivas, de seguridade social e de proteção social e 5) aspectos relacionados com a cultura e com os valores sociais legitimados pela sociedade (SOLAR; IRWIN, 2010).

Os determinantes intermediários referem-se ao conjunto de elementos categorizados em circunstâncias materiais (como condições de moradia, características da vizinhança, condições de trabalho, qualidade do ar, acesso e disponibilidade a alimentos, água), fatores comportamentais (estilos de vida e comportamentos, que se expressam, entre outros, nos padrões de consumo de tabaco, álcool e na falta de atividade física), biológicos (fatores genéticos) e psicossociais (estressores psicossociais, circunstâncias estressantes, falta de apoio social). Nesse marco conceitual, o sistema de saúde é considerado um determinante intermediário da saúde, reconhecendo principalmente a influência das barreiras de acesso. A coesão social e o capital social atravessam as dimensões estrutural e intermediária (SOLAR; IRWIN, 2010). 
Figura 2. Modelo dos Determinantes Sociais da Saúde proposto por Solar e Irwin

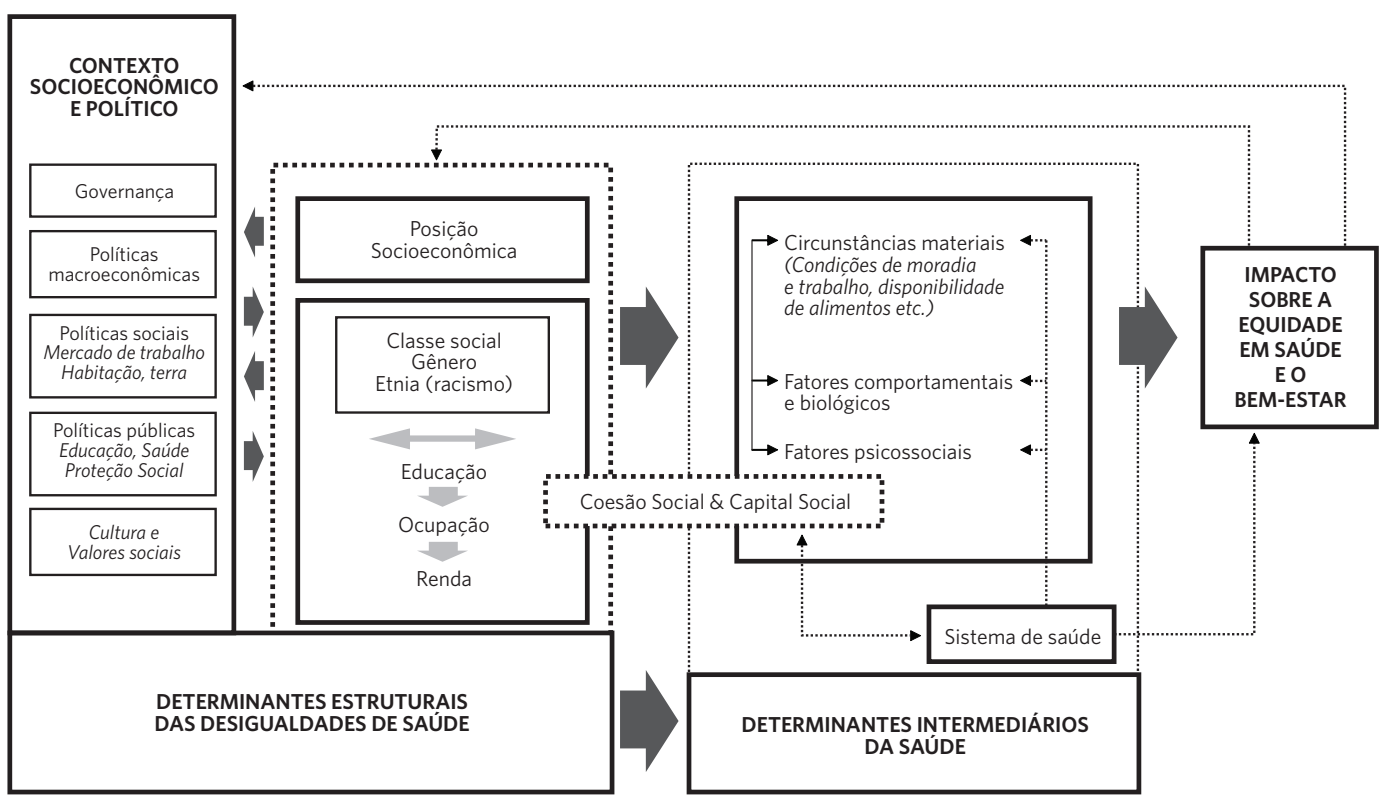

Fonte: Solar e Irwin (2010).

As causas estruturais são projetadas em ambos os modelos conceituais em formatos bastante diferenciados, alcançando posições de relevância e significação distintas. No modelo proposto de Dahlgren e Whitehead (figura 1) tais causas aparecem muito perifericamente (a 'camada' mais fina da figura), sob a denominação de 'determinantes distais, ou macrodeterminantes econômicos e sociais'. Entende-se que a projeção periférica dada aos determinantes estruturais nesse desenho esquemático, somada à ênfase dada à camada intermediária das 'condições de vida e de trabalho', assim como a dos fatores individuais (como idade, sexo e fatores hereditários), traduz a pouca importância conceitual que foi atribuída a estes na construção dessa noção de DSS.

Já no modelo de Solar e Irwin (figura 2) adotado atualmente pela OMS, as causas estruturais assumem uma posição de destaque, mais próxima ao alcance da ideia de 'raiz' ou 'base', representando a prioridade causal (que foi dada neste marco conceitual) aos fatores estruturais na geração das iniquidades em saúde e na modulação das condições de vida. Além disso, o desenho de Solar e Irwin, ao explorar o recurso gráfico da seta, dá projeção à compreensão das relações e conexões entre os determinantes estruturais e os determinantes intermediários da saúde.

Breilh (2013) entende que essa abordagem inscrita no marco conceitual proposto por Solar e Irwin, apesar de representar um paradigma de transição crítica que se abre para a percepção do 'estrutural', começa a romper com uma visão mais restritiva da epidemiologia convencional, sem que isso represente uma mudança de paradigma.

Muitas críticas têm sido estabelecidas a essa abordagem da OMS sobre os determinantes sociais da saúde. Essas críticas têm sido articuladas especialmente por meio de debates no interior da saúde coletiva e da medicina social latino-americana, circulando ao redor da diferenciação entre determinante sociais da saúde e a determinação social do processo saúde-doença (ARELLANo; ESCUDERO; CARMONA, 2008; TAMBELLINI; SCHÜTZ, 2009; NOGUEIRA, 2009; BREILH，2013; ALBUQUERQUE; SILVA, 2014; GARBOIS; SODRÉ; DALBELLO-ARAUJO, 2014, BORDE; HERNANDEZ-ALVAREZ; PORTO, 2015). 
Entendem, em geral, que a OMS aborda os determinantes sociais da saúde sob o ponto de vista de 'fatores' (condições de vida, de trabalho, de moradia, de educação, de transporte etc.), 'contextos', 'circunstâncias' e 'condições', adotando, assim, uma perspectiva reducionista e fragmentada da realidade social. Isso ofusca sobremaneira o entendimento dos múltiplos processos socioeconômicos, culturais, ecobiológicos, psicológicos que compõem as articulações dinâmicas do objeto saúde-doença, uma vez que não reconhece que o perfil patológico é criado e transformado por cada sociedade em diferentes momentos históricos, ao mesmo tempo que converte as estruturas sociais em variáveis e não em categorias de análise do movimento de produção e reprodução social (TAMBELLINI; SCHÜTZ, 2009; ARELLANO; ESCUDERO; CARMONA, 2008; BREILH, 2013).

Breilh (2013) afirma que essa perspectiva de abordagem é reducionista, pois oculta categorias analíticas de peso dentro das ciências sociais (como reprodução social, modos de produção, relações de produção etc.) e torna difícil proporcionar um pensamento crítico direto sobre a essência da organização social da sociedade de mercado e do regime de acumulação capitalista, por meio dos processos de geração e reprodução da exploração humana e da natureza e as suas marcadas consequências na saúde.

Conforme Breilh (2013), as 'causas estruturais' das desigualdades sociais em saúde, apesar de assumirem uma posição de maior relevância no último modelo adotado pela OMS (figura 2), ainda aparecem como abstrações esvaziadas de conteúdo crítico e de movimento. Impossibilitam, também, a análise do processo radical de acumulação econômica-exclusão social como eixo de uma reprodução ampliada das desigualdades sociais (em saúde).

Muito embora ambos os modelos assumam ideias-chave da produção crítica latino-americana da década de 1970, como as dimensões do 'geral', do 'particular' e do 'singular', essas não foram reconhecidas como contribuições latino-americanas originais (BREILH, 2013). Além disso, essas dimensões foram transformadas em níveis de variáveis ou fatores causais, em modelos que trabalham com ações de governança limitadas e funcionalistas, uma vez que acabam por limitar superação das desigualdades sociais em saúde ao plano da 'melhoria das condições de vida' e à ideia de 'repartir recursos', limitando a saúde a um bem de justiça distributiva a cargo do Estado (BRELLH, 2013; ARELLANO; ESCUDERO; CARMONA, 2008). Em outros termos, trata-se de uma abordagem que não reconhece a incompatibilidade entre o regime de acumulação capitalista e os modos de vida saudáveis (BREILH, 2013).

Esse posicionamento foi assumido pela Associação Latino-Americana de Medicina Social (Alames) - e publicado pelo Centro Brasileiro de Estudos de Saúde (Cebes) - no ano de 2011. Nessa colocação, solicitou-se que o conceito de determinantes sociais não fosse banalizado ou reduzido, mas que fosse lembrado que por trás de todo reducionismo do conceito estava uma clara ideia de mercantilização da vida. Uma ideia incitada por um poder hegemônico neoliberal que se expressa em uma propriedade intelectual que beneficia a indústria médica, assim como em diferentes estratégias de manipulação do pensamento coletivo, que possuem a mídia e os meios de comunicação como veículos centrais nesse processo (CEBES, 2011).

No plano da epistemologia científica, Garbois, Sodré e Dalbello-Araujo (2014) problematizam a visão sobre o 'social' presente na noção de determinantes sociais da saúde. Os autores partem de leituras críticas produzidas por Boaventura de Sousa Santos (2008) e Latour (2012) em relação ao modelo de racionalidade científica elaborado na modernidade, para colocar em análise e produzir questionamentos em relação ao recorte que tal modelo imprime aos estudos científicos sobre o social (GARBOIS; SODRÉ; DALBELLO-ARAUJO, 2014). 
Nessa análise, esclarecem que o paradigma que dá base a esse modelo impõe uma separação total entre a natureza e o ser humano, exalta a quantificação, a divisão e fragmentação dos elementos componentes da realidade a ser investigada, a centralidade da ciência estatística e, principalmente, favorece o rigor enrijecido da objetividade e da neutralidade científica (GARBOIS; SODRÉ; DALBELLOARAUJO, 2014; SANTOS, 2008). Além de fragmentar, essa racionalidade demarca o social como domínio específico e circunscrito, como algo distinto dos demais, como biologia, direito, geografia, psicologia etc., e útil apenas para explicar os aspectos residuais que as outras disciplinas não contemplam (LATOUR, 2012). Nesse sentido, configura-se a visão de um social fragmentado e externo à dimensão saúde (GARBOIS; SODRÉ; DALBELLO-ARAUJO, 2014).

Esse modelo foi inicialmente desenvolvido no âmbito das ciências naturais, a partir da revolução científica do século XVII, tendo como atributo necessário a enunciação de leis universais. Apoiava-se no princípio do determinismo, fundado a partir da ideia de ordem e estabilidade do mundo, e anunciava que a natureza é regida por constantes e regularidades e que caberia à ciência descobri-las. Aplicado ao campo da investigação científica, esse princípio resultou na premência dada à busca das relações de causalidade entre os fenômenos (SANTOS, 2008). Nos séculos seguintes (XVIII e XIX), os pressupostos que apoiaram o desenvolvimento dos métodos de excelência para a investigação dos fenômenos naturais foram considerados como igualmente oportunos para basearem a investigação dos eventos sociais, especialmente a partir da corrente filosófica positivista (SANTOS, 2008).

Nessa discussão considera-se pertinente revisitar os argumentos que foram concebidos no bojo do desenvolvimento da racionalidade científica moderna no campo da sociologia, mais especificamente, da sociologia positivista de Émile Durkheim, no intuito de desvelar os preceitos filosóficos que sustentam a noção de determinantes sociais da saúde. Nesse campo, Émile Durkheim (1858-1917) é considerado um dos autores clássicos, aquele que trouxe grande influência na sua consolidação enquanto disciplina acadêmica, inspirando-lhe rigorosos procedimentos de pesquisa. A partir da delimitação e investigação de um considerável número de temáticas, esse autor deu-lhes definição sociológica própria e uma parcela considerável de sua obra foi dedicada à discussão do método de pesquisa adequado à instituição de uma ciência social.

\section{A noção positivista de 'determinantes sociais'}

Segundo Löwy (2009), a ciência social positiva de Durkheim possui como preceito central a noção de 'lei social natural'. Esse pressuposto considera que os acontecimentos humanos podem ser explicáveis 'naturalmente', visto que compartilham a condição de constância e regularidade, a mesma com que se interpretam os fenômenos naturais. A consequência epistemológica decorrente desse pressuposto foi a de que os critérios, regras e procedimentos usados para a pesquisa das sociedades deveriam ser iguais aos utilizados pelas ciências naturais. Por mostrarem-se subordinadas aos mesmos métodos das ciências naturais, as ciências da sociedade deveriam limitar o estudo dos fenômenos sociais à observação e à explicação causal, tornando possível interpretar os 'fatos naturais' que regem as relações humanas e sociais (LÖWY, 2009).

Da mesma forma que as ciências naturais eram reconhecidas como sendo objetivas, neutras, livres de juízo de valor, as ciências sociais também deveriam proceder, usando o mesmo modelo de objetividade científica. Assim, a concepção positivista afirmava a possibilidade de que as ciências sociais se desvinculassem de todos e quaisquer tipos de julgamentos de valor e de ideologias (LÖWY, 2009). 
Em 'Regras do método sociológico', Durkheim (2007) estabeleceu as principais regras que considerava necessárias para que a sociologia se tornasse uma ciência autônoma, procurando demonstrar que poderia haver uma ciência sociológica objetiva e científica, tal qual as ciências físico-matemáticas. Para isso, tal esfera de conhecimento precisaria constituir e delimitar o seu próprio objeto de investigação: o fato social.

É fato social toda maneira de fazer, fixada ou não, suscetível de exercer sobre o indivíduo uma coerção exterior; ou ainda, toda maneira de fazer que é geral na extensão de uma sociedade dada e, ao mesmo tempo, possui uma existência própria, independente de suas manifestações individuais (DURKHEIM, 2007, P. 13).

O fato social, como um objeto passível de observação e explicação científica, precisaria apresentar características bem definidas: a exterioridade, ou seja, a capacidade de revelar-se independentemente dos indivíduos; a coercitividade, mostrando-se capaz de exercer uma imposição sobre os pensamentos e sentimentos dos indivíduos; a generalidade, isto é, a capacidade de mostrar-se comum a todos ou à maioria dos indivíduos a partir de determinadas maneiras de pensar, agir e sentir (DURKHEIM, 2007).

Por apresentarem-se como realidade externa, anterior aos indivíduos, em outras palavras, elaboradas por gerações anteriores às existências atuais, a 'internalização' dessas maneiras coletivas de agir e pensar se dá por intermédio da educação. Esta, segundo o autor, consiste em um contínuo esforço por socializar o indivíduo no meio em que vive, impondo, desde os primeiros anos de vida, maneiras de agir, de sentir e de ver às quais não chegaria de forma espontânea, como comer e dormir em horários regulares, ter hábitos higiênicos, ser obediente e paciente, estudar, trabalhar. Aos poucos, essas maneiras de agir vão dando lugar a hábitos e tendências que resultam dessa coerção (DURKHEIM, 2007).
A abordagem científica dos fenômenos sociais enquanto 'fatos' traz como consequência a primeira regra essencial do método sociológico: considerá-los como 'coisas'.

É coisa, com efeito, tudo o que é dado, tudo o que se oferece, ou melhor, se impõe à observação. Tratar fenômenos como coisas é tratá- los na qualidade de dados que constituem o ponto de partida da ciência. Os fenômenos sociais apresentam incontestavelmente esse caráter. (DURKHEIM, 2007, P. 28).

O caráter de 'coisa' atribuído à análise científica da vida social retira dos indivíduos a ideia ou noção que fazem dos fenômenos e se foca nas representações estabelecidas pela coletividade, materializadas por meio de normas jurídicas, de valores econômicos etc.

Dessa regra fundamental, Durkheim (2007) extraiu as subsequentes. Uma delas diz respeito à necessidade de o pesquisador estabelecer um afastamento de suas pré-noções, de seus preconceitos, das ideias formadas e cristalizadas pelo senso comum, para que aquele possa realizar a observação dos fatos sociais. Esse afastamento requer do sociólogo um rompimento com conceitos formados em domínios exteriores ao científico e que o autor julga como falsas evidências. A ciência seria o lócus de um saber neutro, desprovido de julgamentos de valor. Dessa maneira, o sociólogo, em uma investigação científica, dirigindo-se a um grupo determinado de fenômenos, deveria defini-los previamente. Essa regra é colocada como a condição primeira e indispensável para que exista a possibilidade de prova e verificação dos fatos (DURKHEIM, 2007).

Essa definição, segundo o autor, deve ser a mais objetiva possível, de maneira que seja capaz de exprimir os fenômenos por meio de propriedades inerentes a eles próprios, e não daqueles que provenham de uma ideia do pesquisador. Isso significa que a investigação deve partir das manifestações mais 
exteriores de um fenômeno. Definir os fenômenos sociais a partir de seus caracteres exteriores requer também que o pesquisador os considere naqueles aspectos em que se apresentam isolados de suas manifestações individuais, de forma que sejam representados da maneira mais objetiva possível (DURKHEIM, 2007). Isso quer dizer que o que prevalece é a forma como o fenômeno apresenta-se na coletividade, em sua generalidade.

Fora dos atos individuais que suscitam, os hábitos coletivos se exprimem por meio de formas definidas: regras jurídicas, morais, provérbios populares, fatos de estrutura social, etc. Como estas formas existem de maneira permanente, como não mudam com as diversas aplicações que delas são feitas, constituem um objeto fixo, uma medida constante que está sempre à disposição do observador e que não deixa lugar às impressões subjetivas e às observações pessoais. (DURKHEIM, 2007, P. 45-46).

Vê-se aí, como a propriedade de 'coisa' atribuída ao 'social' retira-lhe a dinamicidade e a organicidade inerentes. Para que os fenômenos sociais possam ser objetivamente abordados, precisam apresentar uma fixidez, uma medida precisa, que se mostre por si mesma e que independa do ponto de vista do pesquisador, eliminando tudo o que tem de variável e de subjetivo.

As regras estabelecidas pelo positivismo de Durkheim não apenas trouxeram, mas, principalmente, legitimaram, no interior das Ciências Sociais, os pressupostos da objetividade, fundamentada na reificação do social enquanto 'fato', a partir de duas características consideradas indispensáveis para a validação científica: a exterioridade, ou seja, a capacidade de mostrar-se como uma realidade independente e externa ao indivíduo e a generalidade, ser comum a todos ou à maioria dos indivíduos. Além de exigir a neutralidade da ciência na análise dos fenômenos sociais, na medida em que colocou como fundamentalmente necessário o afastamento das pré-noções, crenças e preconceitos do pesquisador na observação dos fatos sociais.

Essa caracterização e delimitação do social tornou-o passível de ser isolado, fragmentado e classificado pela ciência. Possibilitou decompô-lo em tantos 'fatores', 'estratos', 'camadas' quanto fossem necessários para que se estudassem e organizassem as relações de causalidade com fenômenos da vida, como o processo saúde-doença. A partir dessas considerações, entende-se ter explanado a maneira pela qual os pressupostos positivistas se inscrevem na mutação de léxico entre determinação social e determinante social. Então, resta apontar, ainda que incipientemente, as consequências de tal alteração, tanto do ponto de vista epistemológico como para a diminuição das iniquidades em saúde.

\section{Considerações finais}

O estudo teve como ponto chave de discussão a noção de determinantes sociais da saúde veiculada oficialmente pela OMS a partir do ano de 2005. Nesse sentido, entende-se que é importante reforçar a diferença entre as noções de 'determinação social da saúde' e a de 'determinantes sociais da saúde'.

A noção de determinação social da saúde foi construída nas três últimas décadas do século XX, a partir de um importante movimento de produção científica da corrente médico-social latino-americana. Essa corrente empenhou-se em trazer suporte teórico para elaboração de um pensamento social na área da saúde, na realização de uma nova leitura da Saúde Pública, a partir de uma perspectiva crítica à abordagem positivista da história natural da doença. Essa leitura crítica foi intensamente marcada por referenciais vinculados ao materialismo histórico, com ênfase nos processos de produção e reprodução social. Retirou do pensamento marxista o 'trabalho' como categoria 
central e assentou no 'processo de trabalho' uma notável importância sobre a determinação do processo de adoecimento.

Anos mais tarde, na entrada do século XXI, a OMS, por meio da criação da já citada comissão, retoma a discussão do social na análise e compreensão do processo saúde-doença, a partir da noção de 'determinantes sociais da saúde'. Essa noção explicita a reificação do social e a necessidade de caracterizá-lo como um domínio específico e limitado da realidade, além de tratá-lo como algo externo ao sujeito coletivo/individual, algo estabelecido 'a priori': uma medida precisa, estática, fixa, ou, nas palavras de Durkheim

[...] um objeto fixo, uma medida constante que está sempre à disposição do observador e que não deixa lugar às impressões subjetivas e às observações pessoais. (DURKHEIM, 2007, P. 46).

Assim, uma revisitação às obras de Durkheim, deixa claros os pressupostos positivistas presentes na ideia de determinantes sociais da saúde, na medida em que desvela os argumentos filosóficos de fragmentação e esquematização dos fenômenos sociais em fatores diversos, passíveis de serem estudados isoladamente, como 'fatos sociais'.

A consequência de operar dessa maneira reforça a disciplinarização e a divisão do conhecimento em 'setores de saber' incomunicáveis. No campo de produção de conhecimento e formação em saúde, encontra-se um exemplo emblemático ao se analisar disciplinas da grade curricular dos diversos cursos que a compõem (a área da saúde), como a sociologia e a psicologia, na qual, na grande maioria das vezes, são ofertadas de modo paralelo e sem relação com as demais disciplinas, colocando-se o social como uma 'dimensão externa' ao indivíduo e à saúde e que podem ser acessados quando se precisa estabelecer frouxas relações com o processo saúde-doença; estabelecendo e reforçando dicotomias entre indivíduo, coletivo, natural, social, biológico. Configuram-se, assim, perfis profissionais desmotivados e despreparados para encarar os desafios que a atualidade impõe e que se expressam na necessidade de conexão de saberes e fazeres. Considera-se que insistir na abordagem de um social fragmentado é escolha de um caminho que se mostra na contramão dos esforços envidados para a construção da interdisciplinaridade.

Em outra perspectiva, Ianni (2011) apresenta os grandes desafios postos na contemporaneidade para o avanço do campo científico, desafios estes que estão ligados às bases históricas sobre as quais se constituiu o pensamento das ciências sociais 'clássicas'. Para a autora, as ciências sociais desenvolveram o seu arcabouço teórico-conceitual de explicação dos fenômenos sociais recorrendo exclusivamente à sociedade, partindo da pressuposição de que tais fenômenos fossem explicados apenas por causas sociais, denegando o universo biológico e o meio externo natural, assim como o indivíduo, e focando apenas nos processos coletivos.

Nos marcos do pensamento moderno, portanto, as questões que permeiam a saúde-doença mantiveram-se polarizadas de forma excludente - o indivíduo e o coletivo, o biológico e o social, as diferentes racionalidades (Ciências sociais - Ciências naturais). Ao biológico, esfera das Ciências naturais, o 'quase imutável', o mundo das leis fixas. Ao social, esfera das ciências sociais, o mundo em transformação, das crises, das revoluções, dos levantes e mudanças históricas, políticas. (IANNI, 2011, P. 34).

Os atuais problemas ambientais, tais como as mudanças climáticas ocorridas em decorrência do aquecimento global, as catástrofes naturais, a diminuição dos recursos hídricos, a diminuição e extinção de espécies, o aumento da produção de lixo e as contaminações de produtos agrícolas por agrotóxicos acabam por desvendar 
a aparente e equivocada divisão entre o natural e o social, uma vez que esses fenômenos são "natureza produzida socialmente, pelas mãos humanas” (IANNI, 2011, P. 35).

No entanto, o presente momento de emergência de profundas mudanças sociais vem forçando a teoria social contemporânea a ocupar-se pelos fenômenos e contextos sociais de sua atualidade (IANNI, 2011, P. 35).

Emergem conceitos como reflexivo, risco, líquido, mundialização, global, cosmopolítico etc. Agora os problemas já não são mais da afirmação de objetos disciplinares da natureza ou da cultura, do biológico e do social (e nem poderiam sê-lo).

Diante desses grandes desafios, entende-se ser urgente abrir um amplo debate sobre os caminhos e trajetórias adotados e sua possível transformação. Um dos pontos é a necessidade da superação do paradigma da disjunção, da redução, da divisão, da fragmentação, que sustenta a ciência moderna (SANTOS, 2008). Isso significa uma reforma radical do pensamento, afirmando um paradigma que dê conta da complexidade, da diversidade, das costuras, das conexões.

Esse movimento de superação do paradigma moderno da racionalidade científica que fragmenta e dispersa o social, tem sido realizado de forma sustentada por importantes teóricos sociais (LATOUR, 2012; SANTOS, 2008). O paradigma emergente se sustenta na condução de uma ciência pós-moderna que ultrapasse a ideia de um mundo controlado e manipulado para a de um mundo que deva ser compreendido e contemplado; um paradigma que afirme a necessidade de que os pressupostos metafísicos, culturais, os sistemas de crenças e sabedorias diversas sejam parte integrante da explicação científica da natureza e da sociedade; um paradigma que supere a dicotomia entre sujeito-objeto, observador-observado, natural-social, mente-matéria, coletivo-individual (SANTOS, 2008).

Latour (2012) sustenta a defesa em uma nova abordagem ao social, que o compreenda como ponto de chegada, de convergência, e não como ponto de partida. Abordagem esta capaz de afirmar que não há nada de específico na ordem social, que o social não deve ser compreendido como uma coisa particular ou como uma realidade específica. Tal abordagem trata de reagrupar, de redefinir e de restabelecer conexões e associações fornecidas por domínios específicos e heterogêneos da realidade de modo a entender os fenômenos a partir de suas incessantes vinculações. Na perspectiva de Santos (2008), trata-se de uma ciência que seja capaz de estudar os fenômenos naturais a partir dos sociais. Isso requer incorporar, para além de métodos capazes de quantificar a realidade, aqueles métodos que possam se debruçar na compreensão da realidade subjetiva do 'outro', da vida em coletividade.

Do ponto de vista das políticas públicas de saúde, entende-se que insistir na separação entre o social e a saúde significa contrariar o princípio da integralidade. Reforça a fragmentação da vida e constrói atalhos contrários às diretrizes do Sistema Único de Saúde. Abordar os acidentes e as mais variadas formas de violência como 'causas externas' ao setor saúde é reduzir a capacidade política de todos os atores sociais para agir perante essas complexas questões sociais.

$\mathrm{Na}$ perspectiva das práticas cotidianas de atenção à saúde, e, tendo como pressuposto que todo ato em saúde é dotado de significação, adotar a noção de 'determinantes sociais da saúde' reforça a polaridade estabelecida entre o ‘ser biológico' e o 'ser social'. É nessa lógica que o sujeito portador de certas doenças específicas, além de ser 'dissecado' pelas diversas especialidades médicas, é desconsiderado como aquele que sofre violência familiar, que vive em condições precárias de vida e de trabalho, que depende das políticas de assistência social para viver. Assim, o ser, em toda a sua complexidade de existência, é partido em distintas dimensões: o ser biológico - 'investigado' por médicos, enfermeiros, fisioterapeutas, dentistas, entre 
outros profissionais de saúde; o ser social, para os assistentes sociais; e o ser psicológico, para os psicólogos. Cabe perguntar em que medida essa postura contribui para a compreensão dos complexos fenômenos humanos e insufla o agir sobre eles.

\section{Colaboradores}

Júlia Arêas Garbois contribuiu substancialmente para a concepção, planejamento do ensaio, elaboração do rascunho e da revisão crítica e participou da aprovação da versão final. Francis Sodré contribuiu substancialmente para a concepção, planejamento do ensaio, elaboração do rascunho e da revisão crítica e participou da aprovação da versão final. Maristela Dalbello-Araujo contribuiu substancialmente para a concepção, planejamento do ensaio, elaboração do rascunho e da revisão crítica e participou da aprovação da versão final.

\section{Referências}

ALBUQUERQUE, G. S. C.; SILVA, M. J. S. Sobre a saúde, os determinantes da saúde e a determinação social da saúde. Saúde em Debate, Rio de Janeiro, v. 38, n. 103, p. 953-965, 2014.

ALMEIDA-FILHO, N. A problemática teórica da determinação social da saúde. In: NOGUEIRA, R. P. (Org.). Determinação Social da Saúde e Reforma Sanitária. Rio de Janeiro: Cebes, 2010. p. 13-36.

ARELLANO, O. L.; ESCUDERO, J. C.; CARMONA, L.

D. Los determinantes sociales de la salud. Una perspectiva desde el Taller Latinoamericano de Determinantes Sociales de la Salud, ALAMES. Medicina Social, v. 3, n. 4, p. 323-335, nov. 2008. Disponível em: <http://journals.sfu.ca/socialmedicine/index.php/medicinasocial/ article/view/260/538>. Acesso em: 2 jun. 2016.

AROUCA, A. S. S. O Dilema preventivista: contribuição para a compreensão e crítica da medicina preventiva. São Paulo: UNESP; Rio de Janeiro: Fiocruz, 2003.
BORDE, E.; HERNANDEZ-ALVAREZ, M.; PORTO,

M. F. P. Uma análise crítica da abordagem dos

Determinantes Sociais da Saúde a partir da medicina social e saúde coletiva latino-americana. Saúde em Debate, Rio de Janeiro, v. 39, n. 106, p. 841-854, 2015.

BREILH, J. Epidemiologia: economia, política e saúde. Tradução: Luiz Roberto de Oliveira. São Paulo: Editora UNESP: Hucitec, 1991.

La determinación social de la salud como herramienta de transformación hacia una nueva salud pública (salud colectiva). Rev. Fac. Nac. Salud Pública, Medellín, v. 31, supl 1, p. 13-27, 2013.

CENTRO BRASILEIRO DE ESTUDOS EM SAÚDE (CEBES). O debate e a ação sobre os determinantes sociais da saúde. Saúde em Debate, Rio de Janeiro, v. 35, n. 90, p. 496-498, 2011.

COMISSÃO NACIONAL SOBRE DETERMINANTES SOCIAIS DA SAÚDE. As causas sociais das iniquidades 
em saúde no Brasil. Rio de Janeiro: Fiocruz, 2008.

\section{COMISSÃO PARA OS DETERMINANTES SOCIAIS}

DA SAÚDE. Redução das desigualdades no período de uma geração. Igualdade na saúde através da ação sobre os seus determinantes sociais. Lisboa: OMS, 2010.

DONNANGELO, M. C. F. Saúde e sociedade. São Paulo: Duas Cidades, 1979.

DURKHEIM, E. As regras do método sociológico. 3 ed. São Paulo: Martins Fontes, 2007.

FACCHINI, L. A. Por que a doença? A inferência causal e os marcos teóricos de análise. In: ROCHA, L. E.; RIGOTTO, R. M.; BUSCHINELLI, J. T. P. (Org.). Isto é trabalho de gente? Vida, doença e trabalho no Brasil. São Paulo: Vozes, 1994, p. 33-55.

GARBOIS, J. A.; SODRÉ, F.; DALBELLO-ARAUJO, M. Determinantes sociais da saúde: o "social" em questão. Saúde Soc, São Paulo, v. 23, n. 4, p. 1173-1182, 2014.

IANNI, A. M. Z. Questões Contemporâneas sobre Natureza e Cultura: notas sobre a Saúde Coletiva e a Sociologia no Brasil. Saúde Soc., São Paulo, v. 20, n.1, p. 32-40, 2011.

LATOUR, B. Reagregando o social: uma introdução à teoria do ator-rede. Salvador: Edufba; Bauru: Edusc, 2012.

LAURELL, A. C. A saúde-doença como processo social. In: NUNES, E. D. (Org.). Medicina social: aspectos históricos e teóricos. São Paulo: Global, 1983, p. 133-158.

LÖWY, M. As aventuras de Karl Marx contra o Barão de Münchhausen: marxismo e o positivismo na sociologia do conhecimento. 9. ed. São Paulo: Cortez, 2009.
NOGUEIRA, R. P. Determinantes, determinação e determinismo sociais. Saúde em Debate, Rio de Janeiro, v. 33, n. 83 , p. 397-406, set./dez. 2009.

ORGANIZAÇÃO MUNDIAL DA SAÚDE (OMS). Diminuindo diferenças: a prática das políticas sobre determinantes sociais da saúde: documento de discussão. Rio de Janeiro, Brasil, 19-21 de outubro de 2011. Disponível em: <http://cmdss2011.org/site/wp-content/uploads/2011/10/Documento-Tecnico-daConferencia-vers\%C3\%A3o-final.pdf>. Acesso em: 16 mar. 2017.

SANTOS, B. S. Um discurso sobre as ciências. 5. ed. São Paulo: Cortez, 2008.

SOLAR, O.; IRWIN, A. A conceptual framework for action on the social determinants of health. Social Determinants of Health. Discussion Paper 2 (Policy and Practice). Geneva: WHO, 2010.

TAMBELLINI-AROUCA, A. Análise dos determinantes das condições de saúde da população brasileira. In: GUIMARÃES, R. (Org.). Saúde e Medicina no Brasil: contribuição para um debate. 4 ed. Rio de Janeiro: Edições Graal, 1984, p. 147-154.

TAMBELLINI, A. M. T.; SCHÜTZ, G. E. Contribuição para o debate do CEBES sobre a "Determinação Social da saúde”: repensando processos sociais, determinações e determinantes da saúde. Saúde em Debate, Rio de janeiro, v. 33, n. 83, p. 371-379, set./dez. 2009.

Recebido para publicação em outubro de 2016

Versão final em janeiro de 2017

Conflito de interesses: inexistente

Suporte financeiro: não houve 